\title{
DIVERSIDADE NEGADA: Vozes de educadores/as sobre bullying na escola
}

Jonas Alves da Silva Junior Rinalva Sales de Oliveira ${ }^{(*)}$

\section{BULLYING: CONCEITO EM CONSTRUÇÃO}

Autores brasileiros, como Abramovay (2009); Schilling (2014); Fante (2011) e ParratDayan (2008) compreendem a violência como uma expressão de amplo sentido que envolve diferentes aspectos, quer seja na forma como se manifesta, quer seja nos espaços sociais em que ela acontece. A escola é um espaço social em que diversos sujeitos interagem. Abramovay (2009, p. 187) a vê como um dos “[...] principais espaços de encontro e convivência, especialmente para crianças, adolescentes e jovens de diferentes níveis e grupos sociais”.

No entanto, nem sempre o encontro e a convivência dos diferentes sujeitos sociais acontecem de forma harmônica. Pesquisas (FANTE, 2011; ABRAMOVAY, 2005, 2009; SCHILLING, 2014) confirmam que uma parcela de alunos/as sofre preconceito e discriminação por serem negros/as, pobres, deficientes, homossexuais, transexuais ou por professarem determinadas religiões. Por isto a escola, de acordo com Schilling (2014, p. 61), “é estudada, também, como lugar da reprodução das desigualdades sociais, das desigualdades de gênero e raça, da produção da pobreza e da exclusão". A mesma autora ainda acrescenta que "a escola entra no debate contemporâneo sobre violência ora como vítima da violência externa, ora como algoz, quando vista como uma instituição com sua cota própria de violência" (SCHILLING, 2014, p. 60).

Alguns estudos sobre violência na escola têm dado destaque ao bullying, caracterizado por Costantini (2004, p. 69) como "um comportamento ligado à agressividade física, verbal ou psicológica", e nessas formas de agressão Guareschi (2008) inclui o ciberbullying, quando o abuso ocorre por meio das redes de relacionamentos na internet.

[...] o bullying possui, ainda, a propriedade de ser reconhecido em vários contextos: nas escolas, nas famílias, nos condomínios residenciais, nos clubes, nos locais de trabalho, nos asilos de idosos, nas Forças Armadas, nas prisões, enfim, onde existem relações interpessoais. (FANTE, 2011, p. 23).

\footnotetext{
${ }^{(*)}$ Jonas Alves da Silva Junior. Doutor em Educação pela Universidade de São Paulo (FE/USP) e Professor Adjunto II da Universidade Federal Rural do Rio de Janeiro (UFRRJ). E-mail: jonasjr@usp.br.

Rinalva Sales de Oliveira. Graduada em Pedagogia pela Universidade Federal do Maranhão (UFMA) e Pedagoga da Secretaria Municipal de Educação de Imperatriz/MA. E-mail: rinalvasales@ hotmail.com.
} 
Ou seja, é um comportamento agressivo que pode ser reconhecido em diferentes contextos sociais em que se estabelecem relações interpessoais, sendo que a escola se configura como um destes, uma vez que se constitui como lugar onde professores, estudantes e funcionários convivem diariamente.

Segundo Fante (2011) e Guareschi (2008) o bullying não se caracteriza como um objeto novo de estudo. As pesquisas iniciaram-se ainda na década de 1970 tendo a Suécia como pioneira, seguido por outros países escandinavos. Na década de 1980 o suicídio de três jovens noruegueses motivou o governo a realizar uma campanha nacional que buscou conhecer os problemas existentes entre vítima e agressor.

Dan Olweus, pesquisador norueguês da Universidade de Bergsten, foi responsável pela criação dos primeiros critérios cuja finalidade era identificar o fenômeno no meio escolar. Por meio de pesquisas, Olweus constatou que a cada sete alunos, um estava envolvido na prática de bullying, no papel de agressor ou vítima (FANTE, 2011).

Esta abordagem histórica mostra que os estudos sobre o bullying já vem se desenvolvendo há algum tempo, principalmente no contexto escolar, porém isto não assegura uma identificação imediata do fenômeno, uma vez que a prática é comumente associada a "brincadeiras próprias da idade" (FANTE, 2011). Em relação ao Brasil, Fante (2011) informa que algumas pesquisas sobre bullying foram desenvolvidas entre 1997 a 2003, pela professora Marta Canfield e seus colaboradores, os professores Israel Figueira e Carlos Neto, e pela Associação Brasileira de Pediatria (Abrapia), respectivamente.

Ainda em relação à pesquisa sobre o bullying em nosso país, Fante (2011, p. 46), avalia que “[...] no Brasil, o bullying ainda é pouco comentado e estudado, motivo pelo qual não existem indicadores que nos forneçam uma visão global para que possamos compará-lo aos demais países $[\ldots] "$.

Por reconhecer a realidade de pouco estudo acerca do tema, porém sem desconsiderar a relevância e a consequente necessidade de aprofundar os estudos relativos ao bullying, Fante (2011, p. 19) afirma ter transformado a temática em curso de pós-graduação, por ela elaborado e coordenado. Em suas palavras ela diz que esta ação visa

[...] estimular a formação de novos pesquisadores e de grupos de estudos para o desenvolvimento de ações de âmbito multidisciplinar e inovadoras a fim de que "permitam detectar [...] o fenômeno não apenas nas escolas, mas nos demais contextos onde se prolifera. 
O termo bullying deriva da palavra inglesa bully (FANTE, 2011; CHARLOT, 2005; GUARESCHI, 2008). Semanticamente, significa valentão, tirano e, como ação, carrega em sua acepção sentidos como brutalizar, tiranizar, amedrontar. Por se tratar de uma palavra de origem inglesa, o termo bullying foi "adotado em muitos países para definir o desejo consciente e deliberado de maltratar uma outra pessoa e colocá-la sob tensão" (FANTE, 2011, p. 27).

Não se trata de um terno universal, já que na Noruega é conhecido por mobbing; no Japão yjime e em Portugal como maus tratos entre os pares. Durante as pesquisas realizadas por Fante, esta diz ter optado em utilizar a expressão maus tratos, como sinônimo para o termo em inglês. Esta decisão foi motivada, segundo a pesquisadora, por verificar que a palavra bullying era pouco reconhecida pelos sujeitos da escola.

Em entrevista à TV Senado, Abramovay (2009) é questionada quanto à sua interpretação a respeito do termo bullying. Sua resposta é que se trata de uma expressão oriunda do norte da Europa e que está relacionada com a violência na escola entre pares, por isto ela não concorda que países da América do Sul, no caso o Brasil, importe um termo como este para falar de uma violência considerada por ela como diferente dos demais países.

Ela diz que o bullying tem a ver com ações repetitivas de um aluno contra outro, é quando um indivíduo atormenta o outro, enquanto que em nosso país a violência nas escolas abrange o tráfico de drogas, o porte de armas, a violência entre professor e aluno e vice-versa. No entanto, mesmo não concordando com a utilização do termo bullying, ela diz que se trata de uma forma de manifestação da violência na escola.

Há autores, como Hirigoyen (2009), que trabalham na perspectiva de identificar o bullying no cotidiano dos casais e nas famílias e também no ambiente profissional. Assédio moral é a expressão utilizada por Hirigoyen (2009) para falar da violência do tipo verbal que causa constrangimento e desestruturação psicológica à vítima. Ela diz que "atos perversos são tão corriqueiros que parecem normais" (HIRIGOYEN, 2009, p. 19). Ou seja, as atitudes de desrespeito entre casais ou de pai para com os filhos em sua maioria são consideradas como normais, porém ao longo do tempo as palavras de ofensas ditas contra uma criança ou adulto, contribuem para que este sujeito se sinta inferiorizado e passe a internalizar como verdadeira as características que lhes são atribuídas.

Fante (2011) explica que as vítimas de bullying sofrem silenciosamente de maneira cruel e velada, maus tratos, humilhação pública, rejeição social, gozações, perseguições, angústias, medos, desrespeito constante e repetitivo, quase sempre por serem diferentes em seu biótipo. $\mathrm{O}$ fato de estar 
fora do que se entende como "padrão" confere ao sujeito a condição de ser maltratado, por meio de palavras ou de forma física, em razão de não se enquadrar nos modelos estabelecidos pela sociedade ou dentro daquilo que esta compreende como aceitável.

No ambiente escolar, esta realidade não é diferente: alguns alunos tratam colegas com desrespeito, seja verbalizando palavrões ou nomeando apelidos em função de sua aparência física, ou porque não demonstram habilidades diante de determinadas atividades propostas. No quesito beleza, existe um padrão imposto pela sociedade, logo se a pessoa não se enquadra dentro deste modelo é inferiorizada, subalternizada e, mais que isso, infra-humanizada.

\section{VIOLÊNCIAS NA ESCOLA E OS SUJEITOS ENVOLVIDOS}

No contexto escolar, as chamadas "brincadeiras", como apelidos e gozações de um aluno/a contra outro se constituem como comportamentos corriqueiros. É uma forma de "brincar" que, na verdade, disfarça o principal intuito de quem está no comando da ação, que é chamar a atenção para algo específico de um colega da turma, seja a cor de pele, o tipo de cabelo ou ainda um comportamento de timidez que este apresenta. Isto é, uma característica física ou comportamental de uma pessoa da turma passa a ser motivo de chacota para um colega ou um grupo de colegas da escola.

Porém são atitudes que ocorrem de modo repetitivo por um determinado tempo e contra uma mesma pessoa. Os estudos que buscam conhecer a realidade da violência no meio escolar consideram essas falsas brincadeiras como bullying. Fante (2011, p. 46) revela que "com base em dados estatísticos obtidos nos mais diversos países, pode-se seguramente afirmar que o fenômeno está presente em todas as escolas do mundo", e sua ação interfere de modo prejudicial no desenvolvimento socioeducacional de alunos e alunas.

Alguns casos e depoimentos colhidos por Fante durante pesquisas realizadas em diferentes escolas, trazem à tona as formas de manifestações que o bullying assume, promovendo resultados negativos na vida social e estudantil do educando.

Janaína, ${ }^{(*)}$ por exemplo, era uma aluna de $3^{\circ}$ ano, cujo apelido recebido pelos meninos de sua sala foi vaca malhada e onça pintada por causa de suas sardas. Outro aluno dizia ser alvo de calúnias porque sempre tirava boas notas. Ele disse que os seus algozes o ameaçavam de bater-lhe caso ele contasse para a direção da escola o que estava ocorrendo. Em depoimento, uma aluna de 9

\footnotetext{
${ }^{(*)}$ Por questões éticas, o nome da escola, bem como de alunos/as e educadores/as citados serão preservados. Assim, para facilitar a leitura utilizamos nomes fictícios.
} 
anos denuncia que sofre com as violências físicas em casa, apanha da mãe, da irmã mais velha, até da avó e dos tios. E quando chega à escola, da mesma forma, alguns meninos agridem-na fisicamente e ainda colocam apelidos nomeados por ela como feios. Nestes relatos, podem-se verificar as diversas formas de manifestação do bullying entre pares no universo escolar.

No primeiro caso ocorre o bullying na forma verbal. A linguagem utilizada pelos colegas deixa Janaína constrangida, e sem ação para responder aos ataques das brincadeiras de mau gosto. No segundo, associa-se a forma verbal à psicológica e se o aluno levar o caso para a direção da escola sofrerá a violência na forma física. Enquanto no depoimento da aluna de 9 anos, a vítima sofre bullying em contextos sociais diferentes (família e escola) e ainda nas formas verbal e física.

Diante de casos como estes, chega-se à conclusão de que a escola perdeu de certa forma sua característica principal que é de agente socializador, para transformar-se em campo inimigo para os/as estudantes vítimas de agressões (GUARESCHI, 2008). Nesta perspectiva, considera-se que a escola deixou de representar um local seguro e protegido para meninos e meninas que convivem com a realidade da violência intramuros. (ABRAMOVAY; RUA, 2002).

Em 2002, Abramovay e Rua realizaram uma pesquisa de abrangência nacional no Brasil. As escolas selecionadas - municipais, estaduais e particulares - estavam situadas em todas as regiões brasileiras. Buscou-se verificar por meio das respostas de alunos e do corpo técnico-pedagógico o que eles já haviam presenciado em relação, por exemplo, à violência contra a pessoa.

A ameaça que, segundo as pesquisadoras, constitui-se em uma forma de violência contra a pessoa, é constituída de "promessas explícitas de provocar danos ou de violar a integridade física ou moral, a liberdade e/ou os bens de outrem" (ABRAMOVAY; RUA, 2002, p. 232). Nesse contexto, a pesquisa mostrou que as ameaças são mais frequentemente mencionadas pelos estudantes de São Paulo e do Distrito Federal. Os dados obtidos nestas duas unidades federativas foram de $40 \%$. As brigas também são formas de violência contra a pessoa.

Brigas e brincadeiras - bobagens - se confundem em uma mesma linguagem, sendo acionadas por situações diversas: briga-se pelo futebol, pelo lanche, por notas; porque foi chamado de feio, de gorda; porque objetos são tomados uns dos outros [...] (ABRAMOVAY, RUA, 2002, p. 236).

A acepção que Abramovay faz em relação às brigas e brincadeiras nas escolas pesquisadas deixa transparecer que elas são banais, uma vez que a motivação se dá em virtude de "coisas pequenas" como o futebol, o lanche, o ser chamado de feio ou gordo. Às palavras brigas e brincadeiras verifica-se que a autora acrescenta o termo bobagens e explica que aquelas se confundem em uma mesma linguagem. Mas estas brigas e brincadeiras seriam mesmo bobagens 
ou poderiam ser vistas como formas da manifestação de violência entre pares, denominadas por outros autores como bullying?

Ainda mencionando a pesquisa feita por Abramovay e Rua (2002), ressalta-se a seguinte declaração:

[...] observa-se que em geral, os alunos são as vítimas mais constantes, seguindo-se os professores e os funcionários/diretores/grupos discriminados. [...] A violência física foi a que mais atingiu a todos, seguindo-se a violência contra a propriedade. Por último veio a violência verbal, a qual, na maioria das vezes, passa despercebida como forma de violência. (ABRAMOVAY; RUA, 2002, p. 298).

Fazendo um recorte desta fala da pesquisadora, três informações chamam a atenção pela relevância e a ordem como foram situadas: os professores ocupam o segundo lugar como vítimas; entre os segmentos sociais da escola há um grupo denominado como discriminados, que são vítimas da violência que ocorre neste ambiente, e a terceira mostra que não se dá muita importância à violência verbal.

Portanto, a violência que se manifesta no meio escolar, seja ela verbal, física e/ou psicológica, vitimiza os diferentes atores que a compõem, e a escola termina sendo lugar também da reprodução das desigualdades sociais e da exclusão e, sem dúvida, impõe àqueles que sofrem estas penalidades o isolamento do grupo como forma de proteger-se.

Fante (2011, p. 15) afirma ser o bullying "um fenômeno social de grande relevância com características peculiares que podem ser identificadas". Ainda de acordo com a autora, os/as estudiosos/as identificam os tipos de papéis desempenhados pelos sujeitos, cinco no total, os quais são bem definidos entre os envolvidos: o agressor e o expectador, enquanto as vítimas podem ser identificadas como típicas, também chamadas de bode expiatório, provocadoras e/ou agressoras. Em relação a estas, e nas explicações que seguem serão enfatizadas somente as características que dizem respeito à vítima típica.

Os autores ou agressores são pessoas que comumente manifestam pouca empatia. Frequentemente pertencem a famílias desestruturadas, nas quais há pouco relacionamento afetivo entre seus membros. A maioria são meninos e tratam-se de pessoas que cultivam ideias de superioridade perante os outros. Admite-se que os que praticam o bullying têm grande probabilidade de se tornarem adultos com comportamentos antissociais e/ou violentos. Já os espectadores, também chamados de testemunhas, são pessoas que não sofrem e nem praticam a violência, mas costumam mostrar-se indiferente ao sofrimento da vítima e não delatam os agressores. 
A vítima típica, ou o alvo de bullying é aquele que sofre as consequências das agressões física, verbal ou psicológica exercidas pelo agressor. Elas, normalmente, passam a demonstrar sentimentos de insegurança e de inferioridade, o que as fazem sentir-se responsáveis pelas agressões sofridas. Outras características são a dificuldade de impor-se ao grupo, tanto física como verbalmente, e uma conduta habitual não-agressiva.

Estas características elencadas têm como base estudos sobre o bullying no ambiente escolar, realizados por Fante (2011) e Guareschi (2008) cujo público investigado foram os/as alunos/as, o que se observa ser esta uma característica predominante nos estudos específicos sobre o bullying neste ambiente. Os/as professores/as, quando citados/as, geralmente ocupam o papel de vítima, e aparecem apenas nos percentuais quantitativos.

\section{METODOLOGIA}

Pesquisar é questionar, indagar, procurar resposta para um problema posto. Encontrando ou não uma resposta ao problema, a pesquisa não se encerra. De acordo com Michel (2005, p. 32) é necessário compreender que a pesquisa “é um processo interminável, intrinsecamente processual”.

$\mathrm{Na}$ tentativa de captar os significados das ações e as relações estabelecidas entre professor/a e aluno/a, foi utilizado como instrumento de coleta de dados o questionário estruturado com questões abertas e fechadas, direcionado aos professores/as de três escolas de Ensino Fundamental, sendo duas privadas e uma pública, todas localizadas no município de Imperatriz (MA).

O objetivo foi conversar com o corpo docente (ao todo 13 professores/as, sendo somente um do gênero masculino) do Ensino Fundamental em um só momento, explicando-lhe a relevância social da temática pesquisada, bem como pedir-lhes que devolvessem o material respondido, logo ao final da reunião.

\section{A FALA E A ATITUDE DOS/AS PROFESSORES/AS SOBRE BULLYING NA ESCOLA}

De acordo com o referencial teórico, o bullying como manifestação de violência ainda é pouco estudado e igualmente reconhecido no meio escolar. O próprio termo ainda soa como desconhecido para muitos/as professores/as e gestores/as, dificultando assim que se promovam ações de prevenção e ou enfrentamento a esta forma de violência que é realidade em qualquer escola independente do status social de seus atores. 
O que os professores/as sabem sobre bullying? E o que fazem diante de situações que caracterizam esta forma de agressão em sala de aula ou em outro espaço da escola envolvendo alunos/as e também professores/as?

Esta seção tem como fim ouvir os professores/as por meio de seus relatos escritos e trazer à tona resposta às perguntas anteriormente destacadas.

Inicialmente foi perguntado "Você sabe o que é bullying?", caso a resposta fosse sim, o professor/a poderia explicar de acordo com o seu ponto de vista o que significa. Somente em uma das escolas privadas uma professora deixou a resposta em branco, e outra marcou a afirmativa não.

Apesar de a professora ter deixado a resposta em branco, ela fez o seguinte comentário: "o termo bullying é novo, só sei que é violência, mas até que ponto, que tipo de violência?” (Moema professora escola privada).

De igual forma, a outra professora que também escolheu a opção não para mostrar seu desconhecimento em relação ao bullying, expressou-se desta maneira: "mesmo usando o termo não, a minha opinião é que procuraram algo pra fazer e não encontraram" (Sandra- professora escola privada).

São duas situações diferentes em que a professora Moema apesar de declarar não saber o que significa bullying, ao mesmo tempo afirma tratar-se de violência, porém questiona até que ponto, e que violência seria bullying. E a professora Sandra, mesmo tendo marcado a opção 'não', deixa transparecer na sua fala que sabe o que é, mas prefere fazer um comentário que demonstra ver o bullying como algo criado por quem não tem coisa mais importante para fazer.

Fante (2011) explica que o público alvo de sua pesquisa, inclusive professores/as, demonstra dificuldade em reconhecer o termo bullying como violência, por isto ela optou em utilizar a expressão maus tratos, como forma de facilitar a compreensão dos respondentes quanto ao que estava sendo investigado. Entretanto, em relação às duas professoras cujas falas foram transcritas, evidencia-se "um desconhecimento" que parece não se interessar muito em descobrir o que é, e como o bullying se manifesta.

A fala da professora Sandra revela de certa forma que ela não atribui importância ao tema, talvez por acreditar que o bullying não passa de um assunto do momento. Às vezes o professor/a desenvolve uma postura de envolver-se apenas no que diz respeito ao trabalho com a sua disciplina e não atenta para outras demandas que surgem no universo educacional e requer dele atenção enquanto educador. 
Foram selecionadas algumas das explicações dadas pelos/as demais professores/as sobre o que significa bullying, a saber:

Os alunos fazem piadas, críticas e até mesmo agem de maneira agressiva e violenta com os colegas que não são semelhantes a eles, como por exemplo, os alunos gordos, usam corte de cabelo, roupas diferentes, algum tipo de deficiência etc. (Luísa - professora escola privada)

É o que chamamos de preconceito, xingamento, palavrões que não devem ser ditos, por exemplo, rotular o colega (Rosa - professora escola pública)

É uma forma de violência calada, que expõe o aluno a situações constrangedoras. (Vera professora escola pública)

Com base em Guareschi (2008), Fante (2011) e Costantini (2004) é possível identificar nos discursos das professoras elementos significativos que em parte caracterizam o bullying e que são derivados de preconceito, com xingamentos e atitudes agressivas para com aqueles considerados diferentes. Segundo Costantini (2004) as expressões atribuídas como significado de bullying compreendem a manifestação do fenômeno nos aspectos físico, verbal e ou psicológico.

Outro elemento característico exemplificado pela primeira professora é a que diz respeito a ser uma manifestação de violência individual ou de grupo: "os alunos fazem piadas..."

A expressão "violência calada" usada pela professora Vera, também se constitui como uma característica típica do bullying. Em maioria alunos/as que são vítimas de bullying sofrem em silêncio e não conseguem pedir ajuda ou delatar seus agressores. Isso contribui para que as agressões perdurem, ocasionando consequências que afetam a saúde física e psicológica da vítima (FANTE, 2011).

"Violência física, moral ou psíquica" (professor Manoel - escola privada). Este professor trouxe um elemento novo na sua explicação, pois fala do bullying como violência moral. Acerca disso, Hirigoyen (2009, p. 19) diz que são "pequenos atos perversos tão corriqueiros que parecem normais", por isso às vezes estão bem presentes no dia a dia dos casais, familiares e funcionários nas empresas.

Na família, por exemplo, termina assumindo uma máscara de educação. Ou seja, os pais usam de palavras grosseiras e repetitivas contra a criança como forma de educá-la, de moldá-la de acordo com o seu ideal de educação para a vida. Não compreendem que este modo de ensinar pode cooperar para torná-la uma pessoa de baixa autoestima, insegura, com incapacidade de autodefesa e talvez uma futura vítima de bullying na escola. 
Em relação à violência moral nas empresas, a relação de poder se estabelece geralmente entre chefe versus subordinado. No dia a dia são direcionadas ao subordinado palavras grosseiras e que põem em jogo sua capacidade profissional, o que acarreta à vítima tensão, sempre que precisa se dirigir ao superior. (COSTANTINI, 2004).

A violência moral acontece também na forma de comentários maldosos que visam a deturpar a imagem de determinada pessoa. Na escola, por exemplo, tanto aluno/a quanto professor/a podem se tornar alvo de "fofocas" em função de sua sexualidade, de uma deficiência, condição social ou religião. Para se manter no anonimato, os agressores, em muitos casos, têm utilizado as redes sociais como ferramenta para espalhar boatos acerca de suas vítimas, o chamado ciberbullying.

Os professores expressaram seu ponto de vista quanto ao significado de bullying. Porém, que postura eles/as assumem quando um aluno/a lhe diz que está sofrendo violência por parte dos colegas?

Algumas falas são bem semelhantes, e retratam a opção do/a professor/a em passar o problema para a frente, ou seja, para a gestão resolver.

$$
\begin{aligned}
& \text { Incentivo ele a procurar a direção para tomar providência (Moema - professora escola } \\
& \text { privada). } \\
& \text { Chamo a coordenação, direção para tomar providência (Ana - professora escola privada). } \\
& \text { Procuro orientá-lo, falar com a coordenação e os pais (Vera - professora escola privada). } \\
& \text { Ouço e levo o caso à coordenação (Manoel - professor escola privada). }
\end{aligned}
$$

Sem dúvida que se faz necessário compartilhar questões como essa com a gestão da escola e às vezes com a família da vítima e do agressor, a fim de que se promova uma relação baseada no respeito e na ética entre os envolvidos. Porém a fala dos docentes remete a um distanciamento do problema que está acontecendo com o/a aluno/a.

Mas há quem faça diferente:

Chamo os alunos que estão fazendo a agressão, converso, caso não resolva levo para a coordenação (Luísa - professora escola privada).

Procuro resolver o problema interagindo com eles da melhor forma possível (Helena professora escola pública).

Tomo imediatamente a medida de conversar com seriedade com os envolvidos mostrando que isso é bullying, falo a palavra e explico o que é e ainda indico à direção o ocorrido para (que) ela também compartilhe no combate a essa postura (Neide - professora escola privada). 
Enquanto uns preferem não se envolver, decidem que o melhor é o aluno procurar a coordenação ou direção da escola, outros intervêm dialogando com os agressores, mostrando para a vítima que ela está sendo ouvida. São atitudes bastante diferenciadas de lidar com uma mesma situação.

A atitude de intervenção por parte do/a professor/a, além de transmitir segurança para o aluno/a que está sofrendo violência, ajuda a construir uma relação de confiança. Mesmo que seja necessário levar o caso à coordenação, as professoras procuraram mostrar preocupação e atenção para com o que a vítima diz estar sofrendo.

Apesar de ter sido transcrita apenas a fala de uma das professoras da escola pública, é importante destacar que as demais (três professoras) participantes da pesquisa apontaram unanimidade em procurar resolver, dialogar com os envolvidos, envolver a família de ambos e também compartilhar com a gestão da escola.

Alguns professores/as preferem não se envolver quando um/a aluno lhe diz que está sendo vítima de violência na escola. Porém, quando a agressão acontece de forma explícita na sala de aula, como o/a professor/a reage?

No questionário, foi relatada a história de João Paulo. Um aluno vítima de bullying, que figura como um dos casos reais apresentados por Cléo Fante no livro Fenômeno Bullying: como prevenir a violência nas escolas. Em seguida, fez-se o seguinte questionamento: enquanto professor qual atitude você tomaria diante deste episódio?

João Paulo, um garoto do $6^{\circ}$ ano, 11 anos, vinha sofrendo perseguições de alguns colegas porque não gostava de jogar futebol. Por ser tímido e sensível, chorava com facilidade e não conseguia responder aos ataques de alguns companheiros de escola, passando a ser rejeitado pelos meninos da turma. Ninguém queria sua participação nos trabalhos em grupos ou nos jogos em equipe. Não tendo outra saída, aproximou-se de algumas meninas e, como resultado, ganhou o apelido de Bicha. Por isso, estava sendo perseguido e humilhado no horário do recreio, como passatempo de vários alunos agressores. João Paulo faltava às aulas com certa frequência, alegando que estava doente, que tinha muita dor de cabeça e que não dormia direito. Seu aspecto era triste e deprimido. Parecia que estava sempre com medo que algo ruim lhe acontecesse. Uma colega de classe disse para a professora que o menino estava pensando em mudar-se de escola, mas temia que lá também fosse alvo de gozações. Ele não sabia o que fazer nem como lidar com a questão. $O$ fato é que estava sofrendo muito e queria unicamente que o deixassem em paz. Certo dia, na aula de Geografia, um aluno chamou João Paulo de viado e disse ao professor que não faria o trabalho com ele.

Primeiramente faria uma reflexão sobre as diferenças. Depois, chamaria, aliás, levaria os dois para a coordenação. No outro dia, trabalharia textos. (Vera - professora escola privada) 
A atitude da professora propõe uma medida pontual para uma situação bem presente no cotidiano, que é o preconceito de gênero/sexualidade, quando o brincar, a escolha da cor da roupa, ou o desenvolvimento de certas atividades profissionais ou esportivas estão fortemente arraigados ao estereótipo da sexualidade que em função do sexo diferencia o papel do menino e da menina na sociedade.

Esta herança cultural internalizada pelos colegas de João Paulo os faz acreditar que jogar futebol é coisa de menino, logo para ele provar sua masculinidade, necessariamente precisa gostar desse tipo de esporte. Sua aproximação com as meninas da sala o remete a uma condição de ser sensível, característica de menina (BEAUDOIN, TAYLOR, 2006).

A utilização de textos no dia seguinte, conforme dito pela professora Vera tendencia a um trabalho de "conscientização" dos alunos, e não à desconstrução do estereótipo da sexualidade, que viria contribuir com o desenvolvimento de habilidade e de valores relativos à tolerância e o respeito às diferenças e individualidade de cada um, independente do indivíduo ser homem ou mulher.

Por que uma pessoa que não gosta ou não desenvolveu a competência para realizar uma atividade, que supostamente todos os seus iguais gostam e têm capacidade de realização, deve se tornar alvo de agressão física e ou verbal? João Paulo, por ser menino, não é obrigado a gostar de futebol e nem tampouco sofrer maus tratos por isto.

É importante rever a forma como a professora Vera conduziria a situação vivenciada em sala de aula. Além do trabalho com textos, passa mais uma vez pela condição de levar o problema da agressão para uma instância maior, no caso a coordenação. Seria isto um modelo de organização da escola, em que não compete ao professor/a resolver com a turma situações tidas como complexas?

O poder do professor é limitado, a escola é que tem o papel de orientar e resolver casos desse tipo (Manoel - professor escola privada)

Esta fala é do professor que trabalha na mesma escola, considera seu "poder" como limitado, o que o impede de resolver problemas de amplitude maior como é o caso da agressão em que João Paulo tem sido alvo dos colegas de turma, não apenas no horário do recreio, mas na própria sala de aula. O professor responsabiliza a escola por uma tarefa que também faz parte do seu papel enquanto agente de socialização.

Por que considerar seu poder como limitado? O que acontece dentro da sala não diz respeito à sua "zona" de intervenção?

A atitude de duas professoras da escola pública quanto ao caso relatado seria: 
Conversaria com os perseguidores, se não resolvesse levaria o fato à direção, coordenação e família. Tomaria as medidas devidas sempre envolvendo os pais. (Antônia - professora escola pública)

Encorajava o aluno a fazer o trabalho, procurava conversar com a turma e em outros momentos eu teria uma boa conversa com o aluno que estava sendo perseguido e faria um acompanhamento melhor com ele, explicando a importância que ele tem por ser uma pessoa. (Rosa - professora escola pública)

A postura da professora Rosa no que diz respeito a encorajar e acompanhar o aluno que estava sendo vítima dos colegas, deixando claro para ele seu valor como pessoa, ajuda-o a romper com um comportamento passivo, característico de quem é vítima do bullying, que não consegue se impor diante dos seus agressores. Por causa das agressões, a vítima do bullying passa a acreditar que é culpada pelo que está sofrendo (FANTE, 2011).

A professora Antônia aborda a possibilidade de não mudança na atitude dos agressores. A verdade é que, para os agressores, nem sempre será fácil deixar de apresentar comportamento agressivo para com aquele que é visto como diferente, uma vez que o próprio contexto cultural familiar, em maioria, é fator determinante na aprendizagem de atitudes de intolerância e preconceito para com quem não se molda ao “padrão de normalidade”. (BEAUDOIN, TAYLOR, 2006)

Em relação à não mudança de atitude dos agressores, outra professora afirma:

Caso essa conversa não resultasse em nada, pediria à coordenação que chamasse os pais da criança (agressores) para conversar com eles e puni-lo de forma adequada. (Luísa - professora escola privada).

Será que a punição vai de fato ser eficaz para que os agressores decidam por deixar sua vítima em paz? Ou a penalidade que eles sofreriam em casa não seria apenas um combustível para alimentar ódio para com a vítima?

A proposta da professora aponta para uma decisão radical em busca de mudança da atitude dos agressores. É bem certo que eles não aprenderam a ser agressores apenas quando chegaram à escola. O preconceito e a ação discriminatória materializada por meio de atitudes de violência são decorrentes de um valor cultural incorporado por eles em seu cotidiano, às vezes bem presente nos discursos, gestos e ações da própria família.

Segundo Abramovay (2009, comportamentos baseados no preconceito e discriminação contra quem parece ser ou é homossexual concentra-se entre os alunos mais novos, por isso ela ressalta a importância da discussão sobre o tema a partir da Educação Infantil, como forma de desnaturalizar os estigmas existentes. A punição como caminho para resolver uma situação de 
hostilidade nem sempre vai propiciar ao indivíduo agressor a reflexão necessária para que ele mude seu comportamento.

Outra pergunta lançada aos professores/as foi: "Você já presenciou um aluno ou professor sendo vítima de bullying na escola em que trabalha?" Pediu-se para relatar o que havia acontecido e qual a atitude do professor/a diante do ocorrido.

Entre os 13 professores/as participantes, quatro disseram não ter presenciado, e uma professora, apesar de ter dito sim, depois explicou: "apenas soube, só dei apoio moral". (Vera professora escola privada).

Verifica-se, por meio da fala dos professores/as, que os casos relatados envolvem sempre os/as alunos/as:

Um aluno disse coisas horríveis ao aluno mais calmo e tímido da sala na minha frente, enquanto três ou quatro alunos riam da atitude (Neide - professora escola privada)

Chamando o colega de mocinha, veado etc. Chamo o aluno para conversar e advirto a turma que esse tipo de tratamento pode chegar a um caso mais sério e com processo etc. (Rosa professora escola pública)

Na sala de aula sempre tem alunos que usam óculos, os outros ficam apelidando de quatro olhos, chamo a atenção e converso com os que estão apelidando. (Antônia - professora escola pública).

Os alunos chamavam uma aluna de "Fiona" a personagem do desenho Shrek, porque ela é gorda e vesga. Falei para os alunos respeitarem a colega além de pedirem desculpas. (Luísa professora escola privada).

As agressões estão relacionadas à violência verbal, porque incluem: humilhação, xingamentos e apelidos. Em apenas um dos casos subtende-se que houve violência física:

Minha atitude foi de separar e levar ao conhecimento da direção, depois conversei com o agressor e o agredido (Moema - escola privada).

Os relatos confirmam a manifestação das microviolências no ambiente escolar. Alunos/as são desrespeitados, maltratados/as e se tornam motivo de chacotas porque possuem uma deficiência física ou apresentam característica física não correspondente ao "modelo" de beleza que a maioria acredita ser o ideal. Infelizmente, são práticas "comuns" e que, apesar de os professores/as recorrerem a conversas como forma de inibir tais comportamentos, é possível que estes continuem acontecendo.

De acordo com a última pesquisa realizada por Fante (2011), as principais motivações dos agressores para a prática dos maus tratos são por serem provocados e por brincadeira. Ou seja, há 
casos em que os agressores reagem a uma atitude provocativa da vítima, pela própria dificuldade de lidar com os conflitos inerentes ao convívio do dia a dia, e há aqueles que maltratam pelo prazer da diversão.

\section{CONSIDERAÇÕES FINAIS}

$\mathrm{Na}$ tarefa de investigar como o professor vivencia a realidade do bullying no cotidiano da escola, foi possível perceber, entre outros aspectos, que há professores/as que mostram desconhecimento e não interesse em relação ao tema. Chegam a considerá-lo como "coisa de quem não tem o que fazer". Não percebem que a escola como espaço social dinâmico depara-se com novas demandas as quais requerem do educador conhecimento, envolvimento e intervenção.

No que diz respeito à manifestação do bullying, a prática de abuso evidencia-se com maior frequência entre alunos/as na forma justamente de imposição de apelidos, demonstração de preconceitos, de discriminação e de xingamentos. A referência para este dado está baseada evidentemente nos relatos dos/as professores/as, haja vista que os/as alunos/as não foram sujeitos participantes da pesquisa. Por isto é preciso levar em conta que nestas escolas pode haver casos de bullying ainda não reconhecidos, em virtude a vítima sofrer em silêncio, por medo e vergonha de expor o que está acontecendo.

As vítimas destacadas nos relatos foram: uma menina que é gorda; a menina negra; o que possui deficiência física; o menino tímido, ou que "parece" ser homossexual. Ou seja, os/as que fogem aos "modelos prestigiados socialmente" se tornam alvos de atitudes preconceituosas e discriminatórias. São casos reais de maus tratos acontecendo dentro de uma instituição concebida como lugar de aprendizado, formação e transformação. Reflexos de uma sociedade que ainda vê as diferenças e a diversidade como sinônimo de desigualdade.

Apesar da visibilidade das agressões ser confirmada pelos/as professores/as, a ação comum na forma de lidar com o problema tem sido o diálogo com o agressor, mostrando para ele que sua atitude não é correta. Sem dúvida, uma intervenção necessária. Porém compreende-se que estes resultados revelam a urgência que se tem de a escola promover ações mais amplas voltadas para o aprendizado da convivência, do respeito e da tolerância para com a diversidade, seja ela de ideias, cor/etnia, sexo/gênero e/ou condição social. Afinal, somos uma sociedade heterogênea e cada um precisa ter respeitada a sua individualidade.

Ações desenvolvidas com base no conhecimento, debates e reflexão, envolvendo toda a comunidade escolar e também a família, podem contribuir tanto na redução quanto na prevenção 
desta forma de violência que tem se propagado especialmente entre os pares e que traz prejuízos para a vida socioeducativa dos envolvidos. É mister que a escola cumpra com o seu papel social, oportunizando ao/a aluno/a o aprendizado da cidadania, do respeito, da igualdade, princípios que norteiam nossa vida enquanto ser social. Ficar alheio quanto a esta responsabilidade é criar condições propícias para o fortalecimento e a prática de atitudes motivadas pelo egoísmo, individualismo e sentimento de superioridade

É relevante também a continuidade de pesquisas que busquem conhecer, por exemplo, o histórico de vida dos agressores, pois se sabe que a violência é resultado de inúmeros fatores, e o conhecimento de uma realidade é que nos habilita a intervir nela com maior eficácia.

A inserção de conteúdos que discutam a temática da violência no currículo da formação inicial e continuada do educador é igualmente necessária para o processo de enfrentamento deste problema, uma vez que o/a professor/a, por meio do seu trabalho em sala de aula, tem oportunidade de estar mais próximo do educando, reafirmando e ressignificando a prática de valores baseados na ética, solidariedade e afetividade.

Portanto, mesmo apontando caminhos para a promoção de um ambiente escolar melhor, em que as relações interpessoais sejam pautadas no respeito e na tolerância, tem-se clareza de que conflitos e agressões em um momento ou outro sempre estarão acontecendo, seja entre alunos/as ou aluno-professor. Pretender erradicar a violência que permeia as relações interpessoais no dia a dia da escola é, sem dúvida, um sonho utópico, uma vez que não podemos extrair do sujeito parte daquilo que o compõe enquanto pessoa.

\section{REFERÊNCIAS}

ABRAMOVAY, Miriam. (Org.). Cotidiano das escolas entre violências. Brasília: Unesco, 2005.

Revelando tramas, descobrindo segredos: violência e convivência nas escolas. Brasília: Rede de Informação Tecnológica Americana - RITLA/ Secretaria de Estado de Educação do Distrito Federal - SEEDF, 2009.

ABRAMOVAY, Miriam; RUA, Maria das Graças et al. (Orgs.). Violência nas escolas. Brasília: Unesco/ DST/AIDS do Ministério da Saúde, Secretaria de Estado dos Direitos Humanos do Ministério da Justiça, CNPq, Instituto Ayrton Senna, UNAIDS, Banco Mundial, USAID, Fundação Ford, CONSED, UNDIME, 2002.

BEAUDOIN, Marie-Nathalie; TAYLOR, Maureen. Bullying e desrespeito: como acabar com essa cultura na escola. Tradução Sandra Regina Nertz. Porto Alegre: Artmed, 2006.

CHARLOT, Bernard. Relação com o saber, formação dos professores e globalização: questões para a educação hoje. Porto Alegre: Artmed, 2005.

COSTANTINI, Alessandro. Bullying como combatê-lo? Prevenir e enfrentar a violência entre os jovens. São Paulo: Itália Nova Editora, 2004.

FANTE, Cléo. Fenômeno Bullying: como prevenir a violência nas escolas e educar para a paz. Campinas: Verus, 2011. GUARESCHI, Pedrinho A.; SILVA, Michele Reis. (Org.). Bullying: mais sério do que se imagina. Porto Alegre: EDIPUCRS, 2008. 
HIRIGOYEN, Marie-France. Assédio moral: a violência perversa no cotidiano. 11. ed. Rio de Janeiro: Bertrand Brasil, 2009.

MICHEL, Maria Helena. Metodologia e pesquisa científica em ciências sociais. São Paulo: Atlas, 2005.

PARRAT-DAYAN, Silvia. Como enfrentar a indisciplina na escola. São Paulo: Contexto, 2008.

SCHILLING, Flávia. A sociedade da insegurança e a violência na escola. São Paulo: Summus, 2014.

\section{RESUMO}

O trabalho objetiva analisar que fatores encontram-se subjacentes à prática do professor que o predispõe a ser vítima ou colaborador do bullying na escola. O referencial teórico baseou-se em Fante, Abramovay e Schilling, que abordam a violência escolar em diferentes matizes. A pesquisa qualitativa foi realizada em três escolas do Ensino Fundamental. Utilizou-se questionário como instrumento de investigação para 13 professores/as. Chegamos à conclusão de que o preconceito e a discriminação permeiam a relação entre pares por meio de brincadeiras e apelidos pejorativos; de que existe dificuldade dos educadores intervirem de modo efetivo diante desta forma de agressão; que há resistência em entender as diferenças e a diversidade como algo positivo e desejável e, ainda, professores/as que reconhecem o bullying como um tema de pouca importância.

Palavras-chave: Violência. Diversidade. Bullying.

\section{DENIED DIVERSITY: TEACHER VOICES ON BULLYING IN SCHOOL \\ ABSTRACT}

This study aims to analyze what factors are underlying the practice of teacher that predisposes the victim or bullying of employees at the school. The theoretical framework was based on authors the Fante, Abramovay and Schilling, addressing school violence in their different shades. The research of a qualitative nature, was held in three schools of elementary school. A questionnaire was used as a research tool for 13 teachers. Thus we come to the conclusion that prejudice and discrimination pervade the relationship between peers through play and pejorative nicknames; that there is difficulty of effectively intervening educators before this form of aggression; there is resistance to understand the differences and diversity as something positive and desirable and also teachers who recognize bullying as a matter of little importance.

Keywords: Violence. Diversity. Bullying. 